\title{
All about "Sharing": Internet, Open Access, the Origin of Life and Complex Diseases
}

\section{Yue Zhang*}

CHUM Research Center, Notre Dame Hospital, University of Montreal, Canada

The sharing is nowadays everywhere and almost for everybody. Could it be good time for scientific publications entering open access era?

Around twenty years ago, I started to "see" the Internet. During those days one could gain open access to a remote system to only the public directories through FTP and Telnet. Then, the Internet came with the development of Hyper Text Markup Language (HTML), and programs (browsers). This gave rise to the World Wide Web (WWW), thanks to it, at least I was told, whose codes were free for everybody to use; consequently we started to say: "Your stuff (i.e. knowledge or information) is nothing, if not sharing (on internet)". I thus made my own website to "share" my "tricks" on morph memory of English words by borrowing mother language Chinese (a morph language) memory. For instance, one could imagine that any words with an initial letter " $j$ ", such as "joy" and "jump", as that I (hereby I connects to both people " I " and also its lower case " $i$ ", roughly like the upper half of $j$, so I (i) is $j$ umping because of "joy" whatever and then we may expand it to other words having initial letter with $j$, such as Jupitor, jolt , jogging. It could sound funny to American students but this may indeed help Chinese students to understand and memorize dozens of words easily since they are definitively good at morph memory. Interestingly, a few days later after the debutant of my homepage, several Chinese students sent me emails to express that they like it. What an amazing first experience!

The open access scientific publication policy, thus I definitively support. About two years ago, I was interesting in making own open access scientific journal together with my friends. The special features include the translation in multiple languages in our planned journal. Another one is the audio version, but my initial intention includes bridging the blind to access the scientific advancements. Once by chance I read one paper from Omics group journals with a possibility of translation of fifty kinds of languages. My initial plan includes just several languages, such as English, German, French, and Chinese, with which my friends in Switzerland are competent to deal. Though four different kinds of languages could be much better than English alone but surely less than fifty kinds of languages, I thus gave up that plan. However, my initial thoughts had other designs, such as a brief general introduction to public so as to share novel findings to public rather than facing only the experts in close fields, also the video version (i.e. something similar to JOVE, for example in [1]), especially for those too busy and/or defective with hearing power whatever). Directly or indirectly associated with journal publications, Omics group journals have been equipped with many other great features, such as digital book, social networking as well as many topical conference organisation.

However, superficially, open-access policy could lead to relatively a bit unfair to non-granted scientists. It actually thus favour those established with huge grants. But it could be under the control with Article Processing Fee (APF) waiver policy. For open access journals, in my opinion, it is necessary to develop a novel impact assessment system, which should particularly include two types of citations: both academic and public ones, e.g. Google citations. If relying on classic Impact Factor (IF) alone, it might raise the possibility that authors have benefited the information from one article in open access journal but tend to cite only one similar paper in high IF journal, particularly the case from top IF journals. It is understandable for authors to do so in that getting in published in those IF journals generate a better chance in current system of both grant application and promotion. It is unfair to open access journals. Of notice, most if not all scientists still judge the quality of manuscripts heavily relying on classic IF and likely refer to the references as discussed if no novel impact assessment tool comes up. The impact of open access will probably not be limited to experts but extend further to the public because of its unlimited access. However, taking into account, open access is so young for around one decade in comparison with the debutant of classic scientific publication policy for hundreds of years, its achievement is great and its future is brilliant.

Now let's touch evolution biology and make some perspectives. The origin of life has been hypothesized to experience story of "sharing" too [2]. Imagining that a group of life elements such as Ribonucleic acid (RNAs) or the like (e.g. mini- chromosomes or archaic cells), which individually differed with comparative advantage in capability such as replication, metabolism, or cell division, may collaborate and gain better survival than single states in the same harsh environment. They could have behaved more like a modern bacterial consortium, with RNAs/mini-chromosomes/archaic cells cross-feeding one another not only genetically but also metabolically. Namely, the collectively genetic complement of the RNAs population could have been far greater than that of any individual "RNAs/the like", thus, owning indeed totipotent. The innovations could easily spread through the population and gave the RNA/the like community enormous evolutionary potential. RNARNA/mini-chromosomes/cell-cell contacts would have facilitated both processes. In view of the community, it is not individual cell lines/ RNAs but the community as a whole that survives and evolves. It was such a community, not any specific RNAs, organism, any single lineage that was our universal ancestor-a genetically rich, distributed, communal ancestor [this work, and 2]. It was also this loose-knit biological unit that ultimately evolved.

Similarly, the commencement of multi-cellularity may be another story of "sharing". At that time, cells have been hypothesized to begin their labour division and share the information with cell-

*Corresponding author: Yue Zhang, CHUM Research Center, Notre Dame Hospital, University of Montreal, 1350 rue Sherbrooke Est, Montréal, Canada, Tel: 1-514-890-8000, Ext: 23875; E-mail: zy1001@yahoo.com

Received September 13, 2012; Accepted September 14, 2012; Published September 17, 2012

Citation: Zhang Y (2012) All about "Sharing": Internet, Open Access, the Origin of Life and Complex Diseases. Human Genet Embryol 1:e104. doi:10.4172/2161 0436.1000e104

Copyright: (c) 2012 Zhang Y. This is an open-access article distributed under the terms of the Creative Commons Attribution License, which permits unrestricted use, distribution, and reproduction in any medium, provided the original author and source are credited. 
Citation: Zhang Y (2012) All about "Sharing": Internet, Open Access, the Origin of Life and Complex Diseases. Human Genet Embryol 1:e104. doi:10.4172/2161-0436.1000e104

Page 2 of 2

cell communications. Some cells have been programmed to be even "altruistic" to self- destruct, i.e. programmed cell death [3,4]. Further, mitochondria take in nutrients and release energy function as power stations for the cell that is also vital for evolutionary inventions and development of the nucleus. It is at the very least that both mitochondria and the nucleus could plausibly be granted primacy in evolution. However, the endosymbiosis that generated mitochondria may restructure the distribution of Deoxyribonucleic acid (DNA) in relation to bioenergetics membranes, leading to a remarkable 200,000fold expansion in the number of genes expressed [5]. This quantum leap in genomic capacity relied on strictly mitochondrial power, and prerequisite to the key innovation en route to multi cellular life [5]. In modern cells and organisms, we have hypothesized that the CRS and GRN alongside mammalian Target of Rapamycin (mTOR) signalling pathway could act as major players for their normalcy [4-6]. It is not unexpected that deregulated multi-cellularity could lead to complex diseases, such as cancer, diabetes, neurodegenerative diseases, and osteoarthritis [6]. Further, the "health" of cells could benefit from the "sharing", whose interruption could cause otherwise cells, tissues and whole organism diseases and some epigenetic therapeutic chemicals could reprogram or reverse those abnormities to normal-like [7-8].

\section{References}

1. Zhang $Y$, Kashyap L, Ferguson AA, Fisher AL (2011) The production of C elegans transgenes via recombineering with the galK selectable marker. J Vis Exp 11.

2. Woese C (1998) The universal ancestor. Proc Natl Acad Sci U S A 95: 68546859 .

3. Zhang Y, Moriguchi H (2011) Chromatin remodeling system, cancer stem-like attractors, and cellular reprogramming. Cell Mol Life Sci 68: 3557-71.

4. Miller SM (2010) Volvox, Chlamydomonas, and the evolution of multicellularity. Nature Education 3: 65.

5. Lane N, Martin W (2010) The energetics of genome complexity. Nature 467 929-934.

6. Zhang Y (2012) New Frontiers of Aging Reversal and Aging-Related Diseases Reprogramming. Medical Advancements in Genetic Engineering 1: e101

7. Wang S, Kanojia D, Lo PK, Chandrashekaran V, Duan X, et al. (2012) Enrichment and Selective Targeting of Cancer Stem Cells in Colorectal Cancer Cell Lines. Human Genet Embryol S2: 006.

8. Moriguchi H, Zhang $\mathrm{Y}$, Mihara M, Sato C (2012) A therapeutic method for the direct reprogramming of human liver cancer cells with only chemicals. 